\title{
Adaptarea Poppleton Allen Sales Aptitude Test (PASAT2000) în România: Implicaţii privind procesul de evaluare a forţei de vânzări în România
}

\author{
Lavinia Tânculescu' ${ }^{1}$ \\ SNSPA-FCRP Bucureşti, Departamentul de Psihologie
}

Daniela Vercellino

SNSPA-FCRP Bucureşti, Departamentul de Psihologie/ OS România

Dragoş Iliescu

SNSPA-FCRP Bucureşti, Departamentul de Psihologie / Testcentral România

\begin{abstract}
The paper discusses the cultural adaptation of the Poppleton Allen Sales Aptitude Test in Romania, describing the translation and adaptation process, the structure of the Romanian normative sample and the psychometric characteristics of the Romanian form of the measure. Also, conclusions drawn are discussed regarding implications of the normative sample, in terms of comparisons between certain criterion groups contained in the normative sample, as well as in terms of comparisons of the Romanian data regarding the existence of sales aptitudes in both sales and non-sales professionals, in different industries.
\end{abstract}

Keywords: selling skills, cultural adaptation, Poppleton Allen Sales Aptitude Test

\begin{abstract}
Résumé
L'article traite de l'adaptation culturelle du Poppleton Allen Sales Aptitude Test en Roumanie, décrivant le processus de transposition et d'adaptation, la structure de l'échantillon normatif et les caractéristiques psychométriques de la variante roumaine de l'outil. Par ailleurs, les conclusions sont tirées et expliquées en tenant compte des implications de l'échantillon normatif, en termes de comparaison entre certains groupes critères qu'il contient mais aussi en termes de comparaison entre les normes roumaines concernant la présence d'aptitudes de vente chez des professionnels faisant partie ou non de la force de vente.
\end{abstract}

Mots-clés: aptitudes de vente, adaptation culturelle, PASAT 2000

\section{Rezumat}

Articolul discută adaptarea culturală a Poppleton Allen Sales Aptitude Test în România, comentând procesul de adaptare, componenţa eşantionului normativ şi caracteristicile psihometrice ale formei adaptate a instrumentului. De asemenea, se discută concluzii şi implicaţii care rezultă din datele normative româneşti, atât în termenii comparaţiilor între anumite grupuricriteriu din interiorul acestui eşantion normativ, cât şi în ceea ce priveşte comparaţia dintre prezenţa abilităţilor de vânzări atât la profesioniştii care fac parte cât şi la cei care nu fac parte din forţe de vânzări din diferite industrii, rezultate din eşantioanele româneşti.

Cuvinte cheie: abilităţi / aptitudini de vânzare, adaptare culturală, PASAT2000

\footnotetext{
${ }^{1}$ Adresa de corespondenţă: lavinia.tanculescu@ro.pwc.com.
} 
De la vânzarea unui produs unui client extern, la vânzarea unei idei în interiorul unei organizaţii sau a unei imagini de companie în comunitate, omul de afaceri se confruntă, astăzi, cu obligativitatea de a părăsi confortabilul unic rol de cumpărător pe care-I juca până mai deunăzi, când oferta era considerabil mai ridicată decât cererea, în aproape orice domeniu, şi de a se plasa în rolul vânzătorului. De aceea, a fi capabil să vinzi a devenit, fără îndoială, una dintre abilităţile cheie pe care organizaţiile sunt interesate să le evalueze la angajaţii săi. $\mathrm{Pe}$ fondul acestei nevoi, începând din 2009, a fost introdus în România primul chestionar de personalitate construit şi documentat într-o manieră riguroasă, special proiectat pentru a măsura acele atribute de personalitate care au o relevanţă şi influenţă directă asupra succesului profesional al unei persoane ca vânzător. Acest aspect deosebeşte PASAT2000 semnificativ de alte chestionare de personalitate, care analizează personalitatea din perspectiva unor atribute mai generale, cotidiene, relaţionate cu viaţa de zi cu zi sau cu contexte profesionale mai extinse.

\section{Măsura: Poppleton Allen Sales Aptitude Test}

Poppleton Allen Sales Aptitude Test (PASAT2000, Chestionarul de identificare a potenţialului de vânzări; Poppleton \& Jones, 2000) este rezultatul unui efort major de revizuire a unui mai vechi chestionar de aptitudini pentru vânzări, PASAT (Poppleton Allen Sales Aptitude Test; Poppleton \& Jones, 1997). PASAT 2000 a fost dezvoltat ca urmare unui efort important de analiză a muncii, efectuată pentru o paletă largă de roluri ce presupun vânzarea de diverse produse şi servicii, către mai multe tipuri de clienţi, în moduri şi medii diferite. În afara comportamentelor care sunt văzute ca fiind eficiente într-un post din domeniul vânzărilor la momentul prezent, analiza muncii a reuşit şi o estimare a tipurilor de comportament pe care vânzători, managerii lor, directorii şi clienţii lor le-au privit ca fiind eficiente în viitor. Analiza muncii a inclus, acolo unde a fost posibil, eşantioane diverse, având în componenţa lor femei, minorităţi etnice, persoane în vârstă şi persoane cu nevoi speciale. Performanţa acestor loturi diverse de participanţi la itemii individuali şi la scalele chestionarului a fost extrem de importantă pentru construcţia instrumentului, având scopul de reducere a distorsiunilor care ar fi putut să apară.

Ca urmare a analizei muncii, au fost definite 3565 de comportamente asociate $\mathrm{cu}$ performanţa în vânzări. Aceste comportamente au generat o serie de 717 itemi iniţiali incluşi în două studii pilot. Ulterior, dintre aceştia au fost selectaţi 153 de itemi care alcătuiesc forma actuală a instrumentului. Participanţilor li se solicită să marcheze, pe o scală cu cinci variante de răspuns (Niciodată/Foarte rar, Rar, Uneori, Frecvent şi Întotdeauna/Foarte frecvent), frecvenţa cu care ei au manifestat, în situaţii din trecut, comportamentul indicat de fiecare item, în comparaţie cu alţi oameni pe care îi cunosc. Acest tip de instrucţiune este oferită participanţilor pornind de la concepţia care stă la baza acestui instrument, şi anume aceea că cei mai buni predictori ai comportamentelor viitoare sunt comportamentele trecute. Prin urmare, participanţii sunt rugaţi să răspundă bazânduse mai degrabă pe modul în care s-au comportat decât pe modul în care consideră că s-ar comporta într-o circumstanţă viitoare.

\section{Descrierea instrumentului: PASAT 2000}

PASAT 2000 are opt scale principale, dintre care cinci încarcă pe un factor de grup principal, denumit „Adaptare continuă între viaţa profesională şi viaţa personală" $(i-v)$, două scale pe un al doilea factor de grup principal, denumit "Control” (vi - vii), iar o ultimă scală încarcă independent pe un factor ce poartă denumirea scalei, respectiv „Încredere în sine" (viii). Toate scalele încarcă pe un factor general denumit "Atitudine pozitivă". O atitudine pozitivă asupra vieţii profesionale apare de-a lungul fiecăreia dintre cele opt scale şi este esenţa factorului general. Acest factor general are itemi comuni cu conceptul de "locus de control" şi, de asemenea, cu conceptul introdus de Witkin de „independenţă de câmp” (Witkin, 1959). În cele ce urmează o scurtă descriere a celor opt scale principale:

- Adaptarea motivaţională se referă la centrarea pe obiectiv şi la căutarea de provocări. Are aspecte comune $\mathrm{cu}$ motivaţia pentru succes al lui McClelland (1961) şi cu modelul auto-actualizării a lui Maslow (1942).

- Adaptarea emoţională se referă la gestionarea eficientă a evenimentelor solicitante din punct de vedere emoţional şi, în mod special, la demonstrarea unei a 
atitudini rezistente, dar în acelaşi timp, flexibile, în situaţii defavorabile.

- Adaptarea socială descrie tendinţa de a stabili şi menţine relaţii eficiente cu ceilalţi. Sociabilitatea pare a sta la baza acestei scale dar este doar una dintre faţetele adaptării sociale.

- Adaptabilitatea descrie capacitatea de a se raporta favorabil la schimbări, de a se adapta la acestea şi, în general, de a avea o atitudine pozitivă faţă de schimbare. Scala are aspecte comune cu factorul Deschidere descris de către modelul „Big Five" al personalităţii.

- Conştiinciozitatea seamănă în mod vădit cu dimensiunea cu acelaşi nume din cadrul modelului „Big Five”. Aceasta se referă la a face lucrurile într-o manieră conştiincioasă, planificată, implicând atenţie la detalii şi respectând regulile.

- Stabilitatea emoţională se referă la controlul stării de spirit.

- Controlul social are în vedere capacitatea de a-i influenţa pe ceilalţi printr-o serie de mijloace, inclusiv prin minciună /înşelătorie.

- $\quad$ Încrederea în sine se referă, în principal, la a avea o părere bună despre propria persoană.

Pe lângă cele opt scale principale, există alte trei scale care deservesc un tip de gestionare particulară ce are legătură cu managementul impresiei create asupra receptorului. Descrierea acestor scale este prezentată mai jos:

- Distorsionarea intenţionată (Managementul impresiei) descrie capacitatea de a fi atent la semnalele sociale transmise de ceilalţi ca linii directoare pentru comportamentul unei persoane.

- Distorsionarea adaptativă (Managementul impresiei) descrie capacitatea unei persoane de a-şi adapta comportamentul pentru a-l urma sau gratifica pe cel al altora.

- Comportamentele intenţionat şi adaptativ sunt privite ca tipuri de comportamente de falsificare pentru că acele comportamente care sunt manifestate nu sunt răspunsuri naturale ale individului ci, mai degrabă, răspunsul acestuia la modul în care el simte că ar trebui să se comporte. Studiile desfăşurate de autori demonstrează că aceste scale au, deseori, legătură cu performanţa individuală (Poppleton \& Allen, 2000)
- Distorsionarea / Falsificarea socială (Gestionarea / managementul impresiei) este o scală compusă din itemi care au tendinţa să fie falsificaţi atunci când respondentul oferă răspunsuri distorsionate. Aceasta poate include nu numai intenţia respondentului de a crea o impresie falsă, dar şi situaţia în care acesta este convins că acela este modul în care el/ea ar reacţiona (auto-amăgire) şi, în general, orice manieră de a se plasa într-o lumină pozitivă.

\section{Metodă}

\section{Procedură}

PASAT2000 a fost tradus şi adaptat pentru România pentru a veni în întimpinarea unei nevoi de evaluare pe care companiile, în special cele cu forţe numeroase de vânzări, le au în mod constant. Având în vedere că angajaţii implicaţi în activitatea de vânzări constituie o categorie foarte volatilă din punct de vedere al aderenţei lor la organizaţie, companiile sunt interesate să selecteze acei profesionişti care să poată genera, în foarte scurt timp de la intrarea lor în organizaţie, venituri. Această nevoie poate fi satisfăcută prin aplicarea PASAT2000, care, însoţit de/împreună cu alte metode şi instrumente implicate în procesul de selecţie, poate asista o companie să evalueze dacă îşi poate permite costul pe care procesul de învăţare al noului angajat, până la atingerea nivelului optim de performanţă, îl impune.

PASAT 2000 poate fi utilizat în mai multe moduri în procesul de selecţie a forţei de vânzări. Poate fi folosit în manieră actuarială, folosind scoruri-limită pentru diferite scale sau folosind modele predictive în selecţia primară. Poate fi, de asemenea, folosit în construcţia unui profil al candidatului sau în luarea unei decizii cu privire la acesta, modalitate potrivită în special atunci când în procesul de selecţie avem un număr redus de candidaţi (de exemplu, în faza finală a procesului, bazată uneori pe lista scurtă a candidaţilor).

Perioada de adaptare a chestionarului s-a întins pe parcursul a 17 luni cuprinse între August 2008 şi Octombrie 2009, perioadă în care au fost culese datele normative pentru România, atât prin procedură creion-hârtie cât şi prin administrare electronică (online). Traducerea chestionarului a fost executată în diade de psihologi, aplicând retroversiunea asupra textului tradus din limba engleză (2 psihologi au tradus chestionarul şi alţi 2 
psihologi au asigurat retroversiunea). Aspectele lingvistice catalogate drept incerte au fost discutate (aspectele problematice survenite au fost mai degrabă de natură lingvistică şi au fost discutate cu un specialist în semantică), iar versiunea finală a fost adoptată în comun de către autorii versiunii româneşti a manualului.

\section{Participanţi}

Eşantionul normativ românesc PASAT2000 este format dintr-un număr de $\mathrm{N}=1119$ de persoane provenind din toate zonele României şi din medii variate. În vederea stabilirii unui eşantion reprezentativ la nivel naţional, informaţiile privind mediul provenienţă, genul şi vârsta s-au bazat pe date publicate de către Institutul Naţional de Statistică. Media de vârstă a eşantionului global este de $\mathrm{m}=27.59$, iar abaterea standard de $A S=6.92$. Din totalul de 1119 participanţi, un număr de $\mathrm{N}=242$ de persoane $(21.60 \%$ din eşantionul total) sunt de sex masculin, iar un număr de $\mathrm{N}=877$ de persoane $(78.40 \%$ din eşantionul total) sunt de sex feminin. Deşi ponderea din perspectiva genului nu pare echilibrată, ea reflectă populaţia de ordin feminin care se află angajată pe teritoriul României în domeniul vânzărilor. În ceea ce priveşte structura eşantionului global, din punct de vedere al mediului de provenienţă, acesta este format din $\mathrm{N}=48$ de participanţi din Asigurări, cu următoarele caracteristici: $10.4 \%$ bărbaţi şi $89.6 \%$ femei, cu vârsta medie de $\mathrm{m}=27.98$ (AS=7.58); $\mathrm{N}=138$ de participanţi din mediul de afaceri Bancar, cu următoarele caracteristici: $15.2 \%$ bărbaţi şi $84.8 \%$ femei, cu vârsta medie de $m=27.54$ ( $A S=6.90) ; N=118$ de participanţi din vânzări autovehicule, cu următoarele caracteristici: $69.5 \%$ bărbaţi şi $30.5 \%$ femei, cu vârsta medie de $m=27.44$ ( $A S=6.95)$ şi $N=662$ de participanţi eşantion normativ (neimplicat în activitatea de vânzare), cu următoarele caracteristici: $44.9 \%$ bărbaţi şi $55.1 \%$ femei, cu vârsta medie de $\mathrm{m}=27.65$ $(A S=7.13)$.

Tabelul 1. Statistici descriptive pentru eşantionul global pentru PASAT2000 în România

\begin{tabular}{|c|c|c|c|c|c|c|c|}
\hline Scală & $\mathrm{N}$ & Min & Max & $\mathrm{m}$ & AS & Asimetria & Boltirea \\
\hline Adaptare motivaţională & 1119 & 38 & 71 & 57.28 & 5.19 & -.13 & .29 \\
\hline Adaptare emoţională & 1119 & 53 & 103 & 80.25 & 8.28 & -.22 & .09 \\
\hline Adaptare socială & 1119 & 58 & 95 & 79.23 & 7.06 & -.28 & -.07 \\
\hline Adaptabilitate & 1119 & 14 & 30 & 22.18 & 2.97 & .07 & -.18 \\
\hline Conştiinciozitate & 1119 & 58 & 107 & 83.91 & 7.25 & .13 & .63 \\
\hline Stabilitate emoţională & 1119 & 32 & 76 & 56.65 & 7.20 & -.17 & .01 \\
\hline Control social & 1119 & 51 & 126 & 88.64 & 11.59 & .23 & -.04 \\
\hline Încredere în sine & 1119 & 16 & 41 & 30.91 & 3.50 & .02 & .08 \\
\hline Distorsiune atentă & 1119 & 9 & 26 & 18.52 & 2.62 & -.02 & .04 \\
\hline Distorsiune adaptată & 1119 & 29 & 47 & 38.32 & 3.11 & -.29 & -.07 \\
\hline Distorsiune socială & 1119 & 41 & 74 & 58.39 & 5.12 & -.19 & -.03 \\
\hline
\end{tabular}

Analiza Tabelului 1 arată faptul că indicii de asimetrie şi boltire se prezintă în limite relativ normale, sugerând o distribuţie simetrică a datelor. Mici excepţii pentru indicii de asimetrie se remarcă la scala de Adaptare socială (-.28) şi la scala de Distorsiune adaptată (-.29). În ceea ce priveşte indicii de boltire, două scale prezintă indici mai ridicaţi, şi anume: Adaptarea motivaţională (.29) şi Conştiinciozitatea (.63); boltirea măsoară înălţimea sau aplatizarea unei distribuţii în comparaţie cu o distribuţie normală; pentru a fi considerată normală, o distribuţie trebuie să nu depăşească \pm 1.96 , ceea ce în cazul de faţă nu se întâmplă (în acest sens au fost luaţi în considerare şi indicii de eroare standard care sunt, pentru asimetrie, situaţi la valoarea de .07 , iar pentru boltire la valoarea de .14); distribuţia datelor relevă aşadar o curbă relativ simetrică şi mediu boltită. 


\section{Rezultate şi discuţii}

\section{Fidelitatea PASAT2000}

Fidelitatea PASAT2000 a fost studiată cu ajutorul coeficienţilor de consistenţă internă alpha Cronbach, calculaţi pentru eşantionul normativ total ( $\mathrm{N}=1119$ persoane) şi pentru eşantioanele masculin ( $\mathrm{N}=242$ persoane) şi feminin $(\mathrm{N}=877$ persoane $)$ considerate separat.

Coeficienţii de consistenţă internă incluşi în Tabelul 2 sunt foarte similari cu cei observaţi şi în cazul variantei originale a testului.
Astfel, scalele de Distorsiune (Distorsiune atentă, Distorsiune adaptată şi Distorsiune socială) au indici de fidelitate mai scăzuţi, în mod special fiind de remarcat aici scalele Distorsiune atentă (.37) şi Distorsiune adaptată (.47). Aceşti indici de consistenţă internă sunt în mod evident plasaţi sub cei consideraţi de limită pentru ca o scală să fie considerată fidelă; totuşi, atragem atenţia asupra faptului că scalele de distorsiune nu sunt utilizate decât ca indicii ale validităţii şi nu contribuie în nici un alt fel la interpretare sau la demersul psihodiagnostic.

Tabelul 2. Indicii de fidelitate Alpha pentru scalele PASAT $2000(\mathrm{~N}=1119)$

\begin{tabular}{l|c|c|c}
\hline Scală & \multicolumn{1}{|c}{$\begin{array}{c}\text { Combinat } \\
(\mathrm{N}=1119)\end{array}$} & \multicolumn{1}{c}{$\begin{array}{c}\text { Masculin } \\
(\mathrm{N}=242)\end{array}$} & \multicolumn{1}{c}{$\begin{array}{c}\text { Feminin } \\
(\mathrm{N}=877)\end{array}$} \\
\hline Adaptare motivaţională & .73 & .64 & .75 \\
Adaptare emoţională & .80 & .78 & .81 \\
Adaptare socială & .86 & .84 & .86 \\
Adaptabilitate & .71 & .49 & .75 \\
Conştiinciozitate & .80 & .75 & .81 \\
Stabilitate emoţională & .74 & .74 & .74 \\
Control social & .84 & .84 & .83 \\
Încredere în sine & .50 & .49 & .51 \\
Distorsiune atentă & .37 & .47 & .34 \\
Distorsiune adaptată & .47 & .49 & .47 \\
Distorsiune socială & .71 & .66 & .72 \\
\hline
\end{tabular}

Pentru scalele diagnostice, indicii de consistenţă internă sunt cuprinşi între un minim de .50 pentru scala Încredere în sine şi .86 pentru scala Adaptare socială, cu o mediană de .77. Cu excepţia scalei Încredere în sine, care are un indice de fidelitate mai scăzut, dar comparabil cu cel caracteristic pentru versiunea originală a testului (autorii instrumentului menţionează şi acceptă un coeficient de fidelitate de .48), toate celelalte scale au indici de consistenţă internă plasaţi peste nivelul .70, pragul minim necesar recomandat de literatura de specialitate pentru ca testul să poată fi utilizat în siguranţă.

\section{Validitatea PASAT2000}

Validitatea de conţinut

PASAT 2000 a fost construit a urmare a unei cercetări extinse în teoriile personalităţii şi clasificării rolurilor din domeniul vânzărilor (Poppleton \& Jones, 2002). Ca urmare a acestor cercetări, au fost desfăşurate un număr de 72 interviuri cu forţa de vânzări, manageri, directori şi clienţi pentru a identifica acele comportamente specifice privite ca extrem de importante pentru obţinerea performanței în muncă. Acestora li s-au adăugat conţinutul manualelor de instruire pentru schemele de evaluare şi a jurnalelor detaliate de vânzări. Ca urmare, au fost obţinute un număr de 717 comportamente distribuite în două chestionare pilot 
administrate forţei de vânzări. A fost luată în considerare 0 unitate de măsurare a performanţei lor în muncă şi au fost reţinuţi acei itemi care asigurat corelaţia dintre răspunsul vânzătorului şi performanţa efectivă în muncă. În plus, itemii care aveau o capacitate bună de discriminare între forţa de vânzare şi personalul care nu era specializat în acest domeniu au fost păstraţi. Acest proces a fost repetat în cazul unui al doilea instrument pilot, care conţinea 270 de itemi care trecuseră de prima cercetare pilot. Cei 153 de itemi finali nu sunt doar cei care au o serie de proprietăţi psihometrice bune, dar sunt şi aceia care corelează cu performanţa în rolul investigat.

\section{Validitatea concurentă}

Un număr de studii de validitate concurentă au fost desfăşurate, studii în cadrul cărora forţa de vânzări a completat instrumentul, luându-se în considerare şi evaluările performanţei lor în muncă (Poppleton \& Jones, 2002)

A rezultat faptul că cele mai fidele unităţi de măsurare a performanţei pentru a fi folosite împreună cu PASAT 2000 sunt indicatorii cantitativi precum volumul de vânzări, depăşirea obiectivului de vânzări sau atingerea acestuia. Cercetările autorilor au indicat faptul că în vreme ce managerii sunt capabili să judece performanţa personalului în termeni generali (de ex. prin a face diferenţa între o performanţă foarte bună şi una medie sau una medie şi o performanţă slabă în muncă), aceştia sunt mai puţini capabili să distingă între nivele atunci când este implicată o scală mai mare de 5 calificative. Autorii (Poppleton \& Jones, 2002) atrag atenţia că trebuie evitat a se folosi clasamentele (prin plasarea personalului din vânzări în ordinea performanţei de la cel mai bun la cel mai slab aşa cum este perceput de către un manager) ca unitate de măsurare a performanţei. Aceasta metodologie nu numai că reduce calitatea datelor obţinute, dar este privită ca fiind o unitate de măsurare a performanţei cu fidelitate scăzută.

\section{Validitatea de construct}

Studiile de validitate au fost realizate în Marea Britanie de către autorii instrumentului şi au la bază instrumente ce măsoară personalitatea, precum Chestionarul de Personalitate Eysenck (EPQ), NEO-PI-R şi Chestionarul de Personalitate Manchester (MPQ) (Poppleton \& Jones, 2002). În cele ce urmează prezentăm câteva corelaţii semnificative cu EPQ si NEO-PI-R. Cercetările realizate în baza acestor chestionare indică corelaţii semnificative la nivelul următoarelor scale: Neoroticismul (EPQ) corelează semnificativ negativ cu Stabilitatea emoţională (ES), Încrederea în sine şi Distorsiunea Atentă din cadrul PASAT 2000 (Poppleton \& Jones, 2002). Extraversia (EPQ) corelează semnificativ pozitiv cu Conştiinciozitatea şi Distorsiunea socială din cadrul PASAT 2000 (Poppleton \& Jones, 2002). Agreabilitatea (NEO-PI-R) corelează semnificativ pozitiv cu Stabilitatea emoţională şi negativ cu Atenţia distorsionată şi Distorsiunea adaptativă.

Corelaţii între scalele PASAT2000. În Tabelul 3 sunt prezentaţi coeficienţii de corelaţie între scalele PASAT 2000. Se observă că majoritatea scalelor corelează puternic între ele cu unele excepţii pe care le vom comenta mai jos.

Spre exemplu, Încrederea în sine nu corelează cu Adaptarea motivaţională, cu Distorsiunea adaptativă, cu Conştiinciozitatea şi cu Controlul social. Lipsa corelaţiei cu scala Conştiinciozitate - care evaluează modul în care o persoană este atentă la detalii şi îşi planifică fiecare acţiune cu grijă - poate fi explicată prin faptul că persoanele care sunt conştiente de valoarea lor nu simt nevoia să pună la punct toate detaliile înainte de a acţiona, ele nu se blochează în planificări minuţioase. Lipsa corelaţiei cu scala de Control social indică faptul că persoanele cu încredere mare în forţele proprii nu simt nevoia să îi convingă pe cei din jur prin apelarea la tertipuri sau induceri în eroare, ci folosesc argumente clare şi obiective în încercarea lor de a convinge.

De asemenea, Adaptarea emoţională nu corelează cu scala de Control social. În general, persoanele care prezintă indici ridicaţi în domeniul Adaptării emoţionale sunt persoane care ştiu cum să gestioneze situaţiile tensionate şi sunt caracterizate de rezistenţă, astfel că această capacitate le conferă stabilitate chiar şi în situaţii atipice, ele nesimţind nevoia de a recurge la o altă formă de control pentru a se adapta situaţiilor cu care se confruntă.

Conştiinciozitatea nu corelează cu Distorsiunea atentă. Persoanele cu un nivel crescut de conştiinciozitate nu simt nevoia să impresioneze prin alte metode şi nici nu consideră că trebuie să se eschiveze atunci când nu au răspunsurile potrivite, ci ele caută să producă argumente logice, făcând apel la planificare şi atenţie la detalii. 
Tabelul 3. Corelaţiile între scalele PASAT2000, calculate pentru eşantionul normativ românesc ( $N=1119)$

\begin{tabular}{|c|c|c|c|c|c|c|c|c|c|c|c|}
\hline Scală & MA & EA & SA & ADA & CON & ES & CS & ASS & $\begin{array}{l}\text { Atten. } \\
\text { Dist. }\end{array}$ & $\begin{array}{l}\text { Adapt. } \\
\text { Dist. }\end{array}$ & $\begin{array}{l}\text { Soc. } \\
\text { Dist. }\end{array}$ \\
\hline $\begin{array}{l}\text { Adaptare } \\
\text { motivaţională }\end{array}$ & - & $.504^{* *}$ & $.570^{* *}$ & $.393^{* *}$ & $.606^{\star *}$ & $.143^{* *}$ & $.141^{* *}$ & .057 & $.212^{* *}$ & $.415^{* *}$ & $.549^{* *}$ \\
\hline $\begin{array}{l}\text { Adaptare } \\
\text { emoţională }\end{array}$ & & - & $.610^{* *}$ & $.434^{* *}$ & $.443^{\star *}$ & $.595^{\star \star}$ & -.063 & $.450^{* *}$ & $-.061^{*}$ & $.325^{\star \star}$ & $.647^{* *}$ \\
\hline Adaptare socială & & & - & $.497^{\star *}$ & $.477^{\star \star}$ & $.387^{* *}$ & $.130^{\star *}$ & $.253^{* *}$ & $.122^{* *}$ & $.463^{\star *}$ & $.743^{\star *}$ \\
\hline Adaptabilitate & & & & - & $.358^{* *}$ & $.238^{* *}$ & $.162^{\star *}$ & $.170^{* *}$ & $.110^{* *}$ & $.370^{* *}$ & $.462^{* *}$ \\
\hline Conştiinciozitate & & & & & - & $.269^{* *}$ & -.008 & -.036 & .037 & $.414^{* *}$ & $.530^{\star *}$ \\
\hline $\begin{array}{l}\text { Stabilitate } \\
\text { emoţională }\end{array}$ & & & & & & - & $\begin{array}{c}- \\
.473^{* *}\end{array}$ & $.356^{\star \star}$ & $.367^{* *}$ & $.372^{* *}$ & $.426^{* *}$ \\
\hline Control social & & & & & & & - & .004 & $.624^{* *}$ & $-.284^{\star *}$ & $.100^{* *}$ \\
\hline Încredere în sine & & & & & & & & - & $.120^{-}$ & -.011 & $.219^{* *}$ \\
\hline $\begin{array}{l}\text { Distorsiune } \\
\text { atentă }\end{array}$ & & & & & & & & & - & $-.118^{* *}$ & $.076^{*}$ \\
\hline $\begin{array}{l}\text { Distorsiune } \\
\text { adaptată }\end{array}$ & & & & & & & & & & - & $.440^{* *}$ \\
\hline $\begin{array}{l}\text { Distorsiune } \\
\text { socială }\end{array}$ & & & & & & & & & & . & - \\
\hline
\end{tabular}

Prescurtări: $\mathrm{MA}=$ Adaptare motivaţională; $\mathrm{EA}=$ Adaptare emoţională; $\mathrm{AS}=$ Adaptare Socială; $\mathrm{CON}=$ Conştinciozitate; $\mathrm{ES}$ = Stabilitate emoţională; $\mathrm{CS}$ = Control Social; ASS = Încredere în sine; Atten Dist. $=$ Distorsiune atenta; Adapt Dist. $=$ Distorisiune adaptată; Soc. Dist. $=$ Distorisiune socială

Notă: * $p<.05 ;{ }^{* *} p<.01$.

Există o serie de corelaţii puternice între scalele PASAT 2000, dintre care unele merită menţionate. Un prim exemplu ar fi cel al scalei de Adaptare motivaţională care corelează puternic cu scala de Conştiinciozitate $(r=.606)$, aspect care poate $\mathrm{fi}$ explicat prin prisma faptului că persoanele conştiincioase, care îşi planifică în mod riguros activităţile, sunt persoane care se centrează pe obiective şi pe atingerea acestora. De asemenea, Controlul social corelează puternic cu Distorsiunea atentă $(r=.624)$, aspect explicabil prin prisma faptului că persoanele care doresc să iasă în evidenţă vor utiliza orice mijloace pentru a se face remarcate. Nu în ultimul rând, Adaptarea emoţională corelează puternic cu Adaptarea socială ( $r=.610)$, relaţie ce indică faptul că persoanele flexibile ştiu cum să gestioneze în mod eficient şi situaţiile stresante sau solicitante din punct de vedere emoţional.

Aceste corelaţii semnificative statistic sunt explicabile prin faptul că toate scalele măsoară acelaşi construct, personalitatea în domeniul vânzărilor. Această situaţie nu este una care trebuie considerată o excepţie în cazul acestor tipuri de chestionare, deoarece ele măsoară aspecte relevante ale aceluiaşi construct global. Situaţia de faţă poate fi considerată similară cu corelaţiile ridicate între scalele testelor de inteligenţă raţională care, măsurând acelaşi factor global „g”, prezintă valori semnificative corelaţionale.

Analiza factorială. Extracţia folosită a fost Maximum Likelihood, urmată de o rotaţie Varimax, respectând în acest sens indicaţiile autorilor instrumentului PASAT 2000. Au fost introduse în analiză doar scalele structurale, cele trei scale de distorsiune fiind excluse. După rotaţie, cei trei factori explică 35.96 , 20.16 şi respectiv $18.89 \%$ din varianţă, totalizând $75 \%$ din varianţa datelor iniţiale. Statisticile de potrivire relevă o potrivire perfectă a datelor cu modelul trifactorial prescris de varianta originală a testului 
$(x 2=73.12, p<.001)$. Analiza relevă trei factori majori, identici cu cei descrişi de autori, anume un factor de Adaptabilitate, unul de Control şi unul de Încredere în sine. Factorul de Adaptabilitate este format din scalele de Adaptare (Adaptare motivaţională, Adaptare emoţională şi Adaptare socială), scala de Adaptabilitate şi scala de Conştiinciozitate; acest factor evidenţiază în mod deosebit cât de uşor poate persoana evaluată să gestioneze dificultăţile cu care se confruntă la slujbă şi în viaţă în general. Factorul Control se referă atât la exercitarea influenţei asupra altora, cât şi la controlul avut asupra propriilor trăiri. Factorul conţine scalele Stabilitate emoţională şi (cu scorare inversă) Control social. Ultimul factor este creat exclusiv din scala omonimă a chestionarului.

\section{Diferenţe demografice}

În funcţie de gen. Din analiza diferenţelor între femeile şi bărbaţii proveniţi din mediul bancar remarcăm că aceştia diferă semnificativ statistic la nivelul a două scale, şi anume: Adaptarea emoţională $(t=2.05 ; p=.04)$ şi Distorsiunea socială $(t=1.40 ; p=.00)$; în ambele cazuri bărbaţii prezintă scoruri mai ridicate decât femeile. Nivelul de adaptare emoţională mai crescut al bărbaţilor poate fi explicat prin prisma faptului că bărbaţii tind să îşi gestioneze mai bine impulsurile şi emoţiile puternice, spre deosebire de femei, care au tendinţa să le manifeste şi să îşi facă de obicei cunoscute trăirile. Scorul mai ridicat al bărbaţilor la scala de Distorsiune socială poate fi explicat prin faptul că bărbaţii au deseori tendinţa de a se ascunde mai mult în spatele unor măşti acceptate şi valorizate social, spre deosebire de femei care au tendinţa de a-şi manifesta în mod explicit emoţionalitatea. Analiza datelor aferente eşantionului care provine din domeniul asigurărilor nu relevă diferenţe semnificative din punct de vedere statistic între femei şi bărbaţi; trebuie totuşi accentuat faptul că volumul acestui eşantion este foarte restrâns, acesta putând fi unul dintre motivele pentru care testul $t$ al semnificaţiei diferenţelor între medii nu pune în evidenţă deosebiri marcante. Testul t pentru eşantioane independente relevă o singură diferenţă între eşantionul de femei şi cel de bărbaţi proveniţi din domeniul vânzărilor de autoturisme, şi anume la nivelul scalei de Adaptare motivaţională, diferenţa fiind remarcată la un prag de $p<.10(p=.59, t=-1.91)$.

\section{Concluzii}

Studiul de faţă este important pentru faptul că aduce în atenţia cititorului posibilitatea de a investiga acele trăsături de personalitate care sunt predictive pentru succesul profesional al profesionistului implicat în activitatea de vânzare. Mai mult, prezintă modul în care, PASAT 2000, un chestionar cu o validitate bună, poate avea un impact major asupra beneficiilor financiare ale companiei care îl utilizează.

Scopul principal al procesului de selecţie la care utilizarea PASAT2000 contribuie din plin este acela de a include în organizaţie angajaţii cei mai buni şi mai productivi. Deşi această afirmaţie este, în mod evident, o formulare suprasimplificată cu privire la un proces complex, scopul ultim al selecţiei este acela de a asigura faptul că angajaţii contribuie la succesul companiei şi produc mai mult decât costă, adică au o contribuţie cu un impact financiar mai mare decât salariul pe care îl primesc şi eventualele alte beneficii (resurse consumate) şi, nu în ultimul rând, produc mai mult decât consumă în cel mai scurt timp de la angajare.

Cercetări viitoare ar trebui să ia în considerare posibilitatea de a compara eşantioane specifice pentru cât mai multe industrii, pentru a identifica dacă există diferenţe semnificative între profesioniştii din domeniul vânzărilor care activează în diferite arii de activitate, dat fiind caracterul particular al obiectului vânzării.

\section{Bibliografie}

Cattell, R.B. and Child, D. (1975). Motivation and dynamic structure. New York. Holt, Rinehart and Winston.

Cattell, R.B., Eber, H.W. and Tatsuoka, M.M. (1970). Handbook of the Cattell 16PF questionnaire. Institute of Personality and Ability Testing. Champaign, Illinois.

Cook, M. (1991). Personnel selection and productivity. Chichester, UK. John Wiley and Sons.

Freud, S. (1920). Beyond the pleasure principle. Standard Education. Ed. 1961, Vol. 18. London, Hogarth Press.

Garbrenya, W.K. and Arkin, R.M. (1980). Factor structure and factor correlations of the self monitoring scale. Personality and Social Psychology Bulletin, 6, 13-22.

Goffman, E. (1959). The presentation of self in everyday life. Garden City, New York. Doubleday Anchor. 
Jones, E. E. (1964). Ingratiation; A social psychological analysis. New York. AppletonCentury-Crofts.

Jones, E. E. (1990). Interpersonal perception. New York. W.H. Freeman and Company.

Maslow, A.H. (1942). A theory of human motivation. Psychological Review, 50, 370-396.

McClelland, D.C. (1961). The achieving society. New York: Van Nintrand.

Paulhus, D.L. (1991). Measurement and control of response bias. In J.P. Robinson, P.R. Shaver and L.S. Wrightsman (Eds.). Measurement of personality and social psychological attitudes. San Diego, Academic Press, 397408.

Poppleton, S. E. (1975). Biographical and personality characteristics associated with success in life assurance salesmen. Unpublished MSc. Dissertation. Birkbeck College, University of London.

Poppleton, S.E., \& Jones, P. (1997). The selection of sales staff. Selection and Development Review, 13, 14-15.

Riordan, C.A. (1989). Images of corporate success. In R.A. Giacalone and P. Rosenfeld (Eds.)
Impression management in the organisation. Hillsdale, N.J. Lawrence Erlbaum Associates, pp.87-104.

Rogers, C.R. (1951). Client centred therapy: its current practice, implication and theory. Boston. Houghton Mifflin.

Rosenfeld, P., Giacalone, R.A. and Riordan, C.A. (1995). Impression management. In $\mathrm{N}$. Nicholson (Ed.), Blackwell dictionary of organizational behaviour. Oxford, UK. Blackwell Publishers.

Roth, D.L., Snyder, C.R. and Pace, L.M. (1986). Dimensions of favourable self-presentation. Journal of Personality and Social Psychology, 51, 867-874.

Roth, D.L., Harris R.N. and Snyder, C.R (1988). An individual differences measure of attributive and repudiative tactics of favourable selfpresentation. Journal of Social and Clinical Psychology, 6, 159-170.

Vernon, P.E. (1950). The structure of human abilities. London. Methuen.

Witkin, H.A. (1959). The perception of the upright. Scientific American, 200, 50-56. 